\title{
SENSITIVITY ANALYSIS AND VALIDATION OF A THERMO-MECHANICAL MODEL OF A SPINDLE
}

\author{
Václav Marek
}
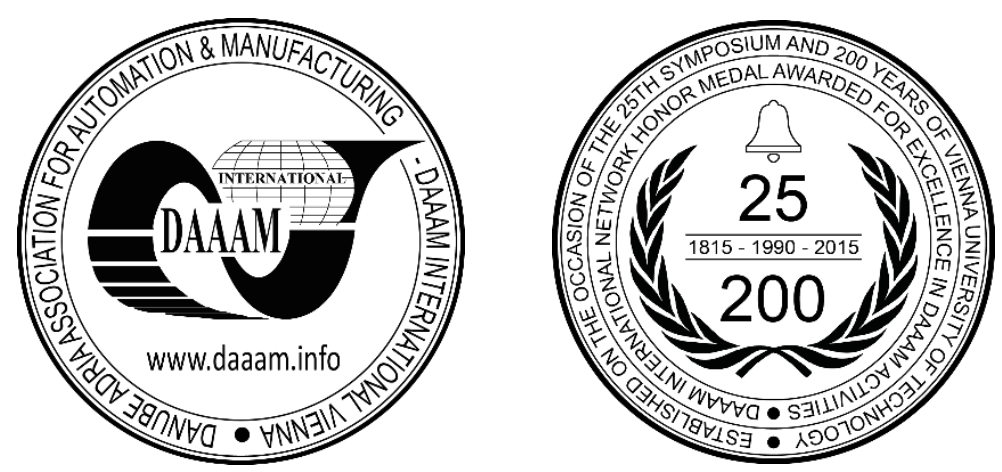

This Publication has to be referred as: Marek, V[aclav] (2018). Sensitivity Analysis and Validation of a ThermoMechanical Model of a Spindle, Proceedings of the 29th DAAAM International Symposium, pp.0703-0708, B. Katalinic (Ed.), Published by DAAAM International, ISBN 978-3-902734-20-4, ISSN 1726-9679, Vienna, Austria DOI: $10.2507 / 29$ th.daaam.proceedings.101

\begin{abstract}
Displacements of milling centres caused by thermal load is a vital issue of a present research. The Final element analysis, the computed fluid dynamic and other predicting tools are strong sources of information about thermo-mechanical behaviour of a machine. Validation and verification of a solution is required as many factors and coefficients influence the solution. The presented study describes the thermo-mechanical behaviour of a spindle of a milling centre. There is demonstrated the thermo-mechanical model and the verification is shown. Simulated data are compared with the measurement. Data generated by simulated options are processed. The goal of this processing is a sensitivity analysis of a thermo-mechanical system. Compensation of thermal displacements of machining spindles is currently a requested issue. Presented sensitivity analysis might help with identification of a critical area of a heat load. Improvements in these areas increase symmetry of warming-up, cooling and other heat distribution parameters. These thermal parameters influence structural displacements. Improvements decrease negative effects of heat loading, such as thermal dilatations and angular deviations. This approach leads to increase the quality and the performance of machining.
\end{abstract}

Keywords: final element analysis; thermal displacements; spindle; validation; verification

\section{Introduction}

The production accuracy of machine tools is effected by the thermo-mechanical behaviour of the components and structural design. Heat distribution and temperature is changed in time due to the time-dependent internal and external heat sources [3], [7], [10]. Generated temperature differences causes thermal induced displacements of the machine structure. These displacements degrade the positioning accuracy and resulting geometrical deviations of manufactured workpiece [6]. Thermal-induced errors might cause up to $70 \%$ of all production errors [1]. Precise design with respect to the thermo-mechanical structure could increase the production quality of a machine tool and it increases the accuracy of the machining. Creation of compensation algorithms is based on thermo-mechanical studies too [9].

For the prediction and the simulation of the complex thermal behaviour are required powerful tools. The complex thermal behaviour consists of heat source locations, intensities, thermal resistances and heat transfer coefficients. Due to the nonlinear thermal deformations, nonlinear modelling approaches are usually used [5]. Methodology of the complex thermo-mechanical model definition is the aim of this paper. 


\subsection{Neural web and AI thermal displacement compensation}

Neural webs and AI principles are perspective trends in a prediction of the thermal induced errors. [5], [11] High precision, accurate CFD/FEM simulation at the beginning of a design is an expensive step with low-value results. The goal of the improvement is a combination of a prediction by a macro-element calculation and a simulation by CFD/FEM. The Macro-model computation provides very fast predictions of a thermal transfer. It is a significantly faster computation. It is not a full substitution of the CFD simulation in this context. It quickly provides basic data for the predictions in the design process. It can be seen in Figure 1 [4], [11].

Non trivial task of derivation displacement by thermal measurement can be solved by artificial intelligence. Application of machine learning is already effective for high accuracy machine tools. AI technology is able to process many information about dilatation effect based on heat load. Algorithm based on machine learning is able to predict displacements in many different cases [13].

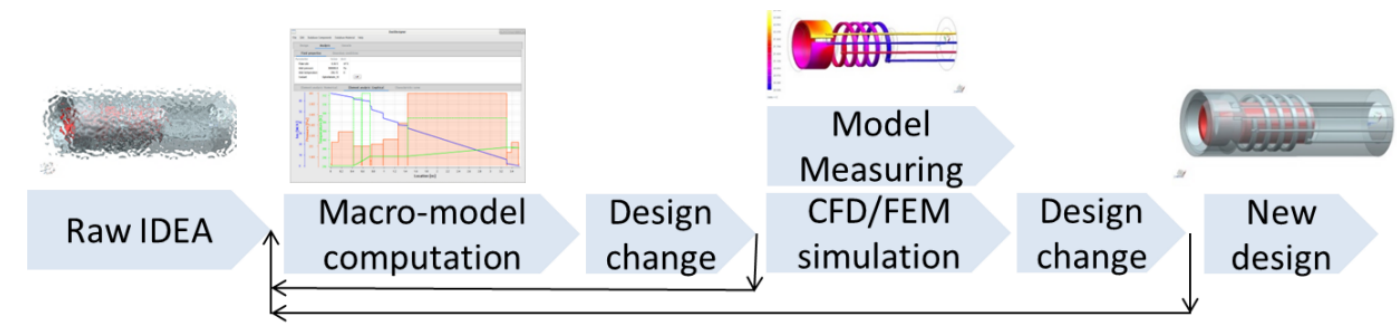

Fig. 1. Computation with super-element predictive computation

\section{Heat sources identification}

Identification of heat sources is the first issue for prediction of heat load. Many studies describe base characteristics of heat sources, which are included in machine tools [2], [4]. A precise definition of heat sources is vital like a definition of boundary conditions for structural analysis [5]. Heat sources can be sorted by position to internal and external. Gears, bearings and electric motors are the main internal heat sources of machines. Sun light, convective heat flows and powerful lamps are the external sources which effect the machine structures. Characteristics of these sources are based on empirical measurements. [8] Figure 2 describes the base identification of heat sources in the spindle case. Equation 1, 2 show examples of base statements of heat loads.

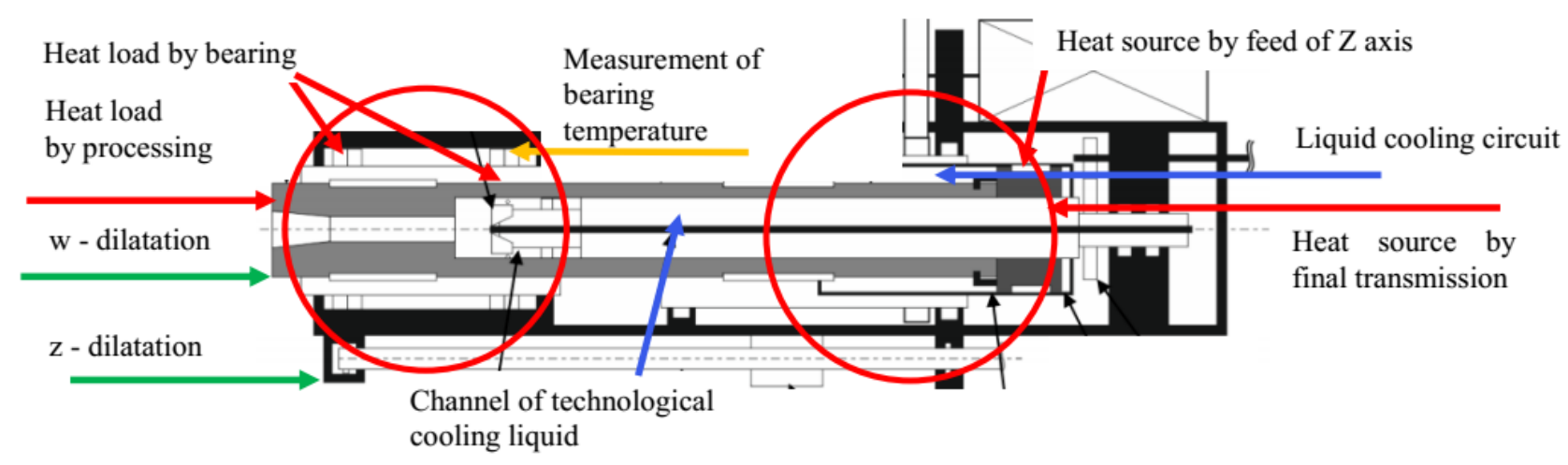

Fig. 2. Heat sources in the spindle case

\subsection{Heat generation in the ball bearing [14]}

$$
\dot{\mathrm{Q}}[\mathrm{W}]=1.05 * 10^{-4} * \mathrm{~F} * \mathrm{r} * \mathrm{n} * \mu
$$

\subsection{Heat generation in gears}

$$
\dot{\mathrm{Q}}[\mathrm{W}]=\mu_{o} * \mathrm{P}
$$

where $\mathrm{F}$ is preload, $\mathrm{r}$ is outer radius, $\mathrm{n}$ is revolutions, $\mu$ is bearing coefficient, $\mu_{o}$ is overall efficiency, $\mathrm{P}$ is performace. 


\section{FEA thermo-mechanical model}

A precision of FEA model is a significant factor for an accuracy of a prediction. Determination of heat sources and heat transitions between bodies are the main factors of a computation. Figure 3 shows the solution setup of the computation. The heat transfer coefficients between bodies, sources of heat load and convection coefficient are defined [7], [3].

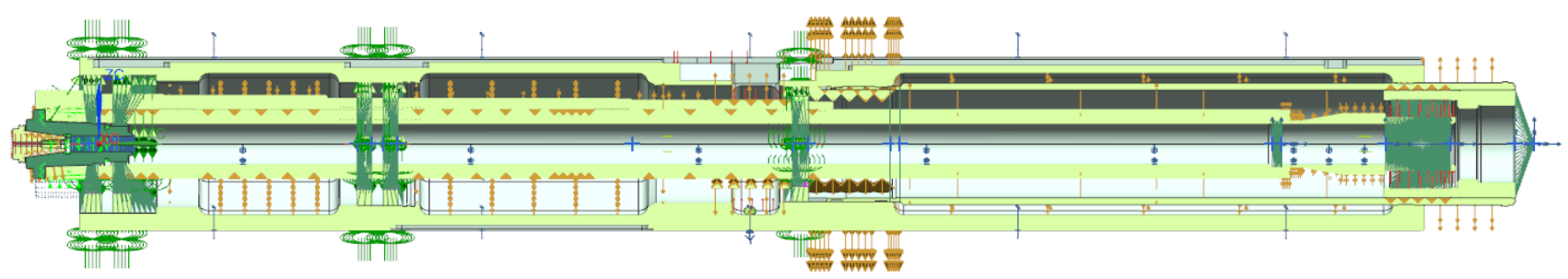

Fig. 3. Thermo-mechanical model, NX12 Simcenter setup

\subsection{Modelling of a heat generation in the bearing}

The study is focused on spectre of revolutions between $600 \mathrm{rpm}$ and 4,000 rpm. Presumed generated heat loads in bearings are written in the Table 1 . The ball bearing FAG DLR with outer diameter $360 \mathrm{~mm}$ is defined: total surface area of balls $79150 \mathrm{~mm}^{2}$. Simplified model is designed, $76608 \mathrm{~mm}^{2}$ surface area for convection, $5138 \mathrm{~mm}^{2}$ for contact; heat transfer coefficient $2500 \mathrm{~W} / \mathrm{m}^{2} \mathrm{~K}$ for surface contact, forced convection area coefficient $30 \mathrm{~W} / \mathrm{m}^{2} \mathrm{~K}$ [7]. Due to the presumed heat conduction in the shaft around $30 \%$ [12], heat permissivity of a bearing is presumed $8,5 \mathrm{~W} / \mathrm{K}$. Numerical simulation indicates that $280 \mathrm{~W}$ of generated heat power is distributed out of the bearing by outer rings to housing and shaft, $120 \mathrm{~W}$ of heat is cooled by convection, based on heat transfer coefficient $30 \mathrm{~W} / \mathrm{m}^{2} \mathrm{~K}$ and flow velocity of rotating air $30 \mathrm{~m} / \mathrm{s}$ [10].

\begin{tabular}{|l|l|l|l|}
\hline Revolutions [ $\left.\mathrm{min}^{-1}\right]$ & Preload [N] & Heat load / bearing [W] & Set of 2 bearings [W] \\
\hline 1000 & 3000 & 164 & 328 \\
\hline 1250 & 3000 & 204 & 408 \\
\hline 1500 & 3000 & 245 & 490 \\
\hline 1750 & 3000 & 286 & 572 \\
\hline 2000 & 3000 & 328 & 656 \\
\hline
\end{tabular}

Table 1. Heat load of bearings

Figure 4 shows solution of heat generation and transfer in the idealized bearing housing. Results of the simulation are comparable with the bearing measurement. Balls in the bearing are simplified, heat generation and convection cooling are defined. These results determine definition of bearing heat load in the overall thermo-mechanical structure. Real simulation is shown in the Figure 4, on the right side. Real simulation indicates heat loading of the rings, it is able to define convection with better accuracy [15] Including the real model of bearing into thermo-mechanical structure of overall spindle case is not perspective. It is because of high computational requirements, quantity of boundary condition and limits of the verification and validation. Computation of the real transient thermal simulation of the bearing for 1 minute running took 60 hours (Xeon $3,4 \mathrm{GHz}, 8$ cores).

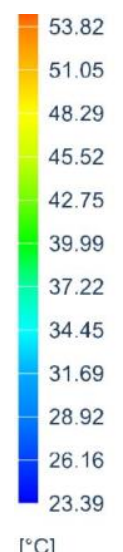

$\left[{ }^{\circ} \mathrm{C}\right]$
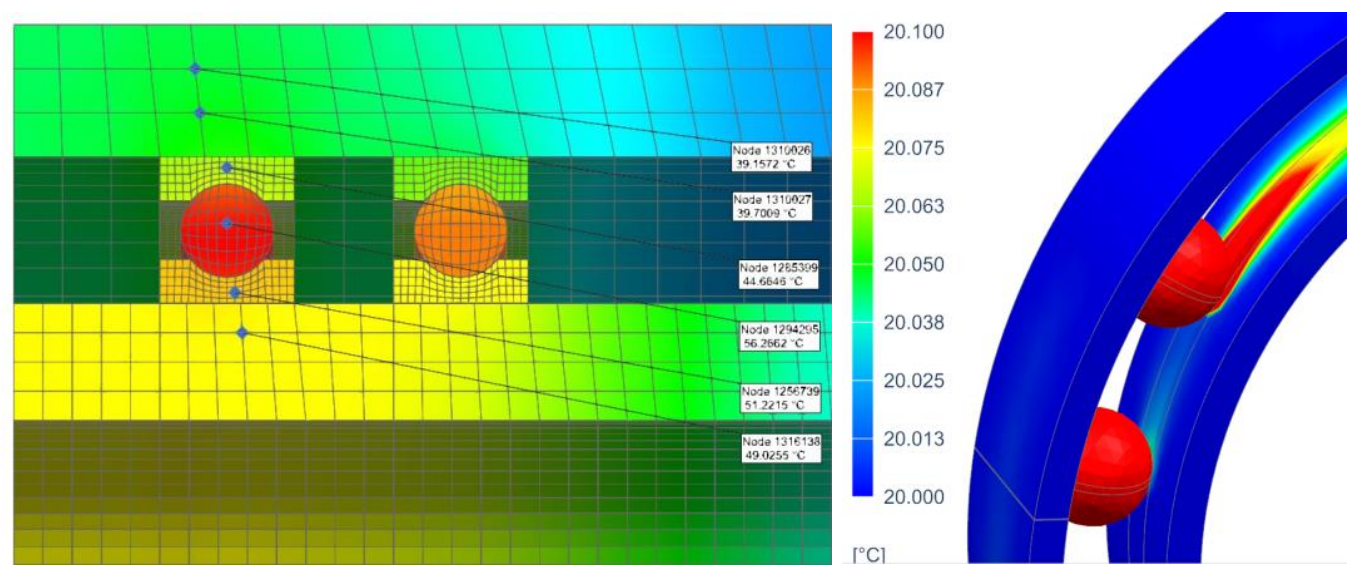

Fig. 4. Thermal model of a bearing, simplified on the left, real on the right 


\section{Sensitivity study}

The thermo-mechanical model of the spindle unit was tested by parameter fields. Parameters can be seen in the Table 2. Displacement of a tool clamping was analysed, depending on parameters. First set of parameters shows variation of loading revolutions. Precision of a model is indicated by presumed dilatation dependent on loading revolutions. The seconds set shows effect of an isolation (heat transfer coefficients - htc) of a spindle body and inner bearing rings. Isolated bearing achieves higher temperature, but average temperature of a spindle body is lower, which means dilatation reduction. The third set represents data for comparison with measurement.

\begin{tabular}{|c|c|c|c|c|c|c|c|c|c|c|c|c|}
\hline & & $\mathrm{z} 0$ & $\mathrm{Z} 1$ & $\mathrm{Z} 2$ & $\mathrm{z3}$ & $\mathrm{z} 10$ & z11 & z12 & z13 & $\mathrm{z} 20 \mathrm{a}$ & $\mathrm{z} 20 \mathrm{~b}$ & $\mathrm{z} 20 \mathrm{c}$ \\
\hline Bearing 12 & $\mathrm{w}$ & 300 & 400 & 500 & 600 & 300 & 300 & 300 & 300 & 300 & 600 & 800 \\
\hline Bearing 34 & w & 300 & 400 & 500 & 600 & 300 & 300 & 300 & 300 & 300 & 600 & 800 \\
\hline Bearing 5 & $\mathrm{w}$ & 150 & 200 & 300 & 400 & 150 & 150 & 150 & 150 & 200 & 400 & 600 \\
\hline Bearing 6 & $\mathrm{w}$ & 200 & 300 & 500 & 700 & 200 & 200 & 200 & 200 & 200 & 500 & 700 \\
\hline Final gear & $\mathrm{w}$ & 300 & 400 & 400 & 400 & 300 & 300 & 300 & 300 & 200 & 300 & 400 \\
\hline F.g. case & $\mathrm{w}$ & 100 & 150 & 200 & 250 & 100 & 100 & 100 & 100 & 150 & 200 & 250 \\
\hline Tool & $\mathrm{w}$ & 120 & 120 & 120 & 120 & 120 & 120 & 120 & 120 & 0 & 0 & 0 \\
\hline Htc & $\mathrm{w} / \mathrm{m}^{2} \mathrm{k}$ & 0 & 0 & 0 & 0 & 400 & 600 & 800 & 1000 & 2000 & 2000 & 2000 \\
\hline Revolutions & $\mathrm{n} / \mathrm{min}$ & 1000 & 1250 & 1500 & 2000 & 1000 & 1000 & 1000 & 1000 & 1000 & 2000 & 2500 \\
\hline Time & $\min$ & $0-60$ & $0-60$ & $0-60$ & $0-60$ & $0-60$ & $0-60$ & $0-60$ & $0-60$ & $0-30$ & $30-60$ & $60-120$ \\
\hline
\end{tabular}

Table 2. Options of a sensitivity study

The thermo-mechanical simulation of a deformation corresponds with the experimental measurement. Simulation in the Figure 6 shows crucial dilatation of a boring spindle. Figure 5 shows the final dilatation with Z13 options. Results of thermal calculation by NX Simcenter solver are exported to structural transient solver NX Nastran and solved with respect to a contact conditions, mechanical structure and preloads [8], [14].

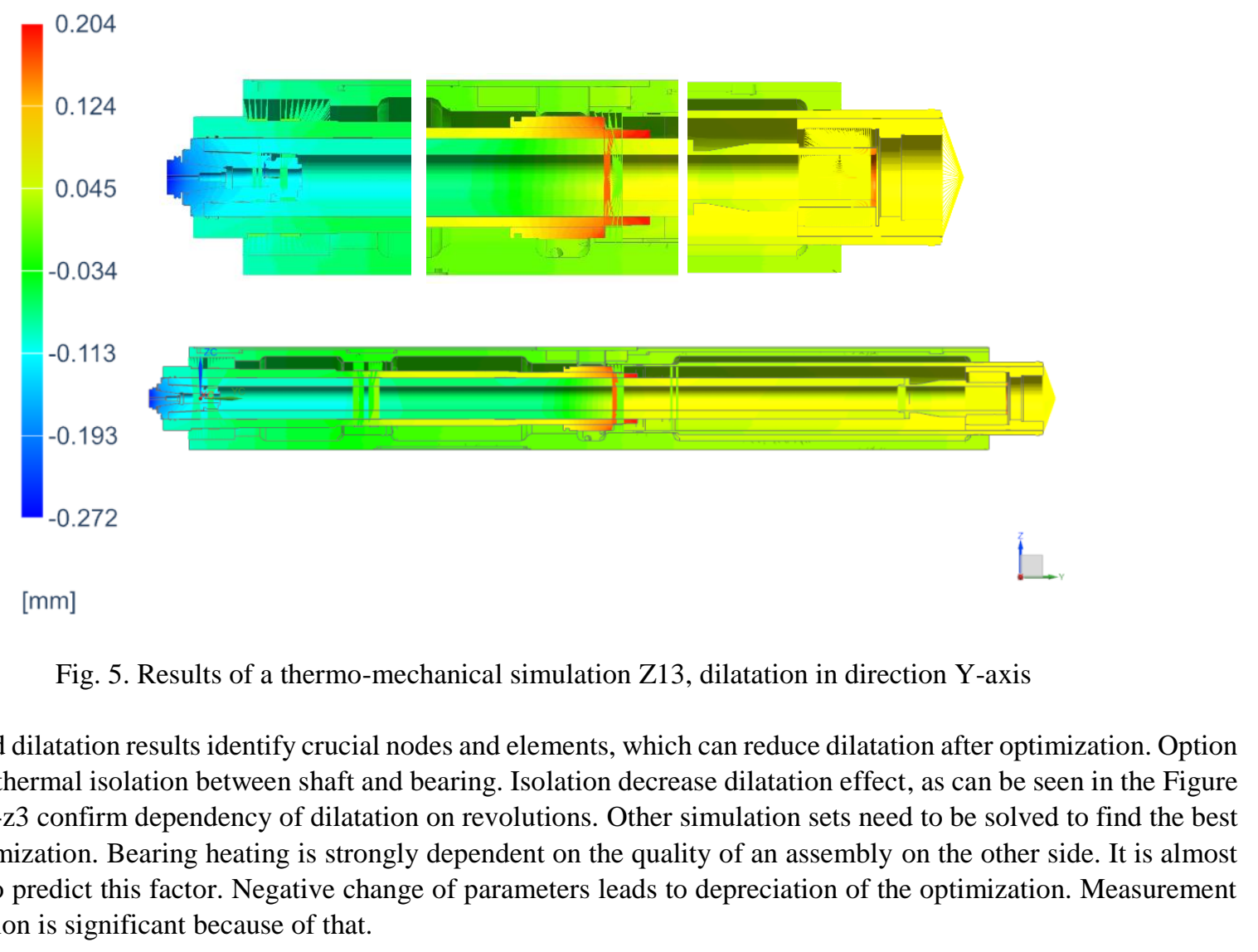

Processed dilatation results identify crucial nodes and elements, which can reduce dilatation after optimization. Option z10-z13 use thermal isolation between shaft and bearing. Isolation decrease dilatation effect, as can be seen in the Figure 6. Option z0-z3 confirm dependency of dilatation on revolutions. Other simulation sets need to be solved to find the best way for optimization. Bearing heating is strongly dependent on the quality of an assembly on the other side. It is almost impossible to predict this factor. Negative change of parameters leads to depreciation of the optimization. Measurement and verification is significant because of that. 

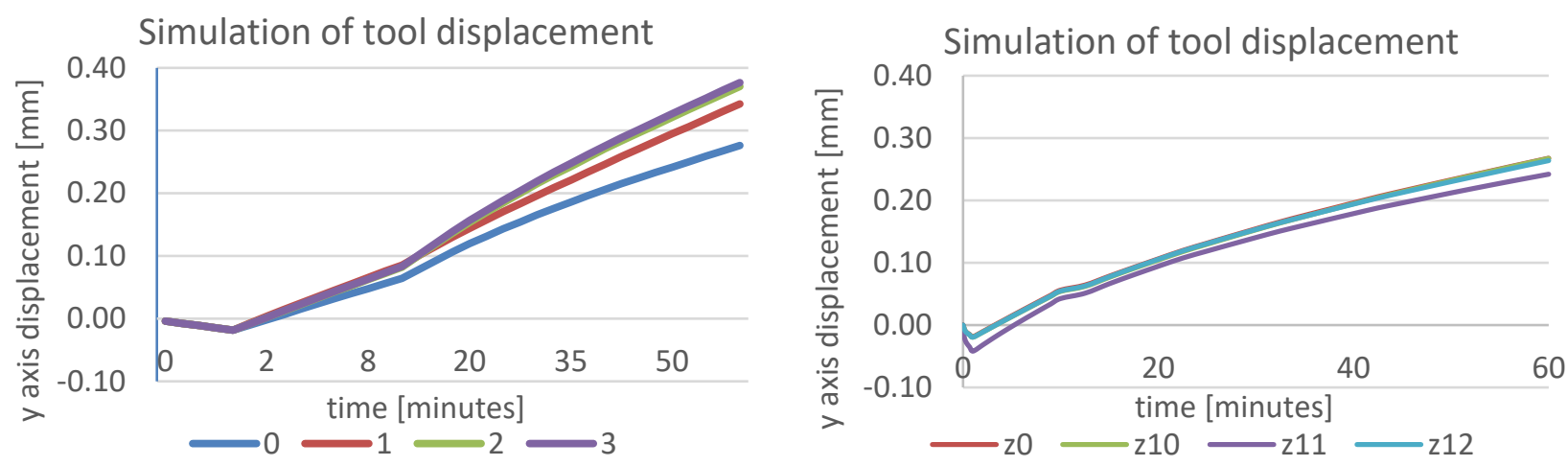

Fig. 6. Graphic results of a sensitivity study

\section{Validation and verification}

Test running was performed by test rig. Running speeds are 1000/min for 0-30 minutes, $2000 / \mathrm{min}$ for 30-60 minutes, 2500/min for 60-300 minutes. Machine run without any process heat loading. Temperature measurement option can be seen in the Figure 7. Results are able for sensors T1, T2, T4. These sensors show temperature of the main spindle bearings. Thermocouples measure body temperatures of housing, actually close to outer ring of bearing.

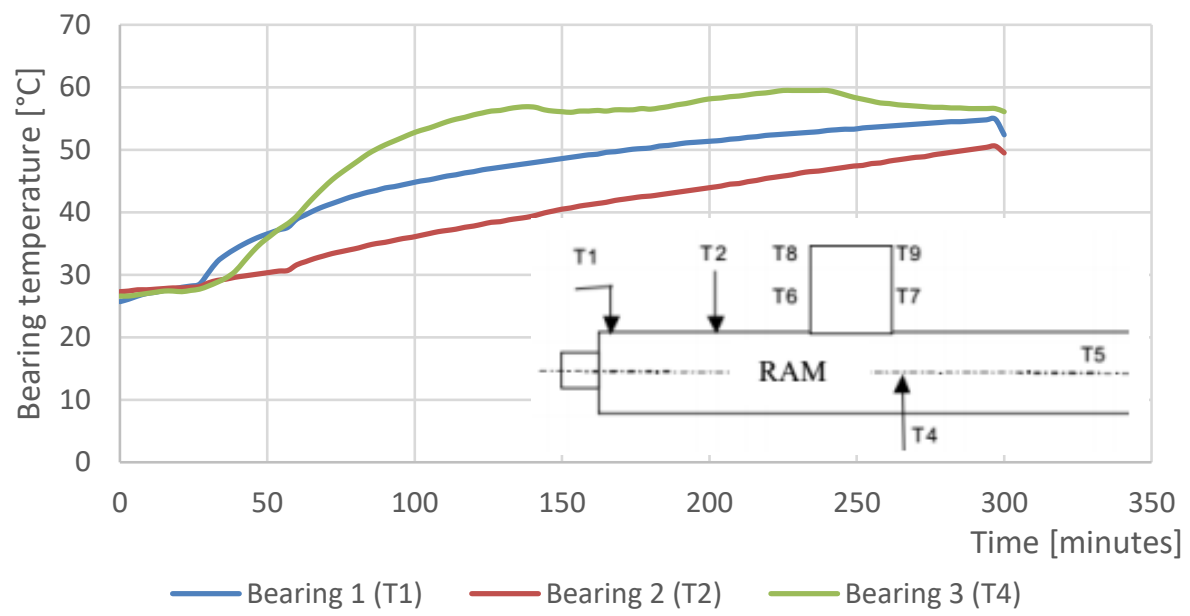

Fig. 7. Measurement options and values

The comparison of the temperature simulation and the measurement can be seen in the Figure 8. Measurement also includes infra-camera pictures which shows thermal effect area around bearings. The simulation responds to the measurement in the time gap 0-7200 seconds.

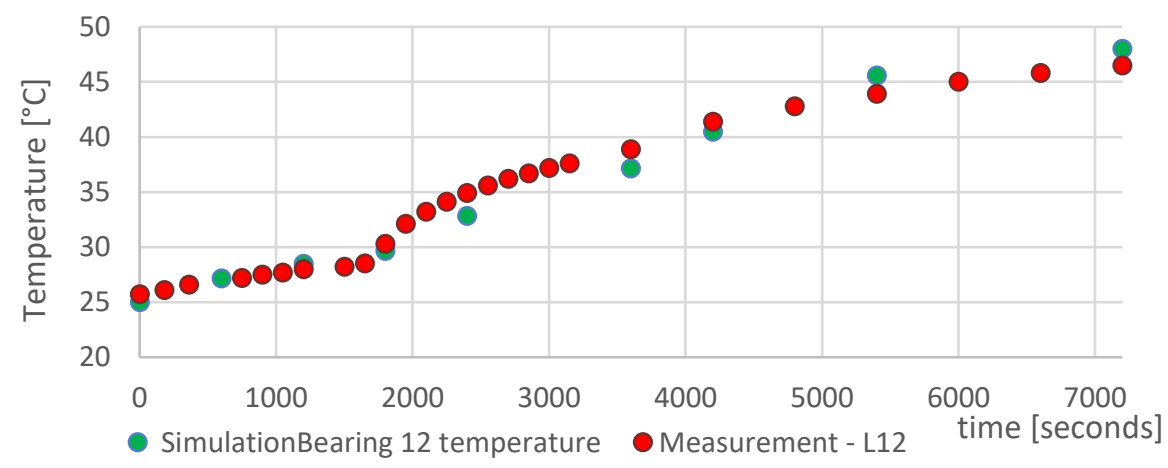

Fig. 8. Heat load of bearing L12 (T1) 


\section{Conclusion}

The simulation and the prediction of a thermal load in the machine tools are high value source of information. The verification of these simulations is required due to wide spectre of used coefficients. Lack of the precise models of these structures motivates research. Described thermo-mechanical model of a spindle was validated by comparison with temperature measurement. The sensitivity study also shows critical nodes of this thermo-mechanical system. The methodology of the thermo-mechanical model definition was stated. The research will continue through detailed verification with detailed boundary conditions. A convection to close environment and specification of bearing cooling by air-oil lubrication will be examined. Gained data and optimized thermo-mechanical models will be applied for the solution of a problem of a spindle dilatation compensation. The solution is strongly requested by machine tool producers. Approach in this area brings optimization of the thermal behaviour of the machine tools and allows increase of the overall machining performance. Described progress induce request of development in affiliated parts of the system.

\section{Acknowledgement}

The project LO1502 'Development of the Regional Technological Institute' is carried out under the auspices of the National Sustainability Program I of the Ministry of Education of the Czech Republic

\section{References}

[1] Bossmanns, B. Tu Jay F. (1999)A thermal model for high speed motorized spindles, School of Industrial Engineering, Purdue University, West Lafayette, IN, USA, Received 8 May 1998; received in revised form 9 January 1999

[2] Min, X; Shuyun, J; Ying, C; (2006)An improved thermal model for machine tool bearings Received 28 November 2005, accepted 27Ferbruary 2006

[3] Florussen, G.H.J., Schijvenaars L.A., Schellekens, P.H.J. (2005) Modelling thermomechanical behaviour of multiaxis machine tools, F.L.M. Delbressine*, Department of Mechanical Engineering, Eindhoven University of Technology, Eindhoven, The Netherlands, Received 8 July 2004; received in revised form 20 January 2005; accepted 4 May 2005

[4] Weck, M., (1995) Reduction and Compensation of thermal Errors in Machine Tools , (I), RWTH Aachen, Laboratory for Machine Tools and Production Engineering (WZL), Germany, Active Member P. McKeown (1 1, Cranfield University, Cranfield Precision Engineering Ltd, UK (retired), Non-Members with Contributions from CIRP Members Noted in the Reference

[5] Yanga, H., Niba, J., (2004) Dynamic neural network modeling for nonlinear, nonstationary machine tool thermally induced error, Advanced Product Center, APC-1, Delphi Corporation-Saginaw Steering Systems, 3900 Holland Ave., Saginaw, MI 48601, USAb, Department of Mechanical Engineering, University of Michigan, Ann Arbor, MI 48109, USA, Received 13 July 2004; accepted 2 September 2004, Available online 2 November 2004

[6] Janda, P., Polak, R. (2016) Virtual Prototyping and Optimization of Heavy Machine Tools. In Annals of DAAAM for 2011. Zadar: Danube Adria Association for Automation and Manufacturing, DAAAM, 2016. s. 967-973. ISBN: 978-3-902734-07-5, ISSN: 1726-9679

[7] Marek, V. (2017). Thermal simulations based on macro-models. 28th International DAAAM Symposium on Intelligent Manufacturing and Automation 2017,. Zadar, ISBN 978-3-902734-11-2

[8] Chval, Z., Raz, K. (2016) Effect of heat load on a mechanical forging press. In Proceedings of the 27th DAAAM International Symposium. Vienna: DAAAM International, 2016. s. 344-348. ISBN: 978-3-902734-08-2, ISSN: 1726-9679

[9] Horejs , O, Mares, M, Hornych, J, (2015) Real-time compensation of machine tools thermal errors including cutting process Journal of Machine Engineering, Vol. 15, No. 3, 2015 Received: 04 August 2015 / Accepted: 18 August 2015 / Published online: 11 September 2015

[10] Bryan JB.(1990) International status of thermal error research. Ann CIRP, 1990;39(2):645-57.

[11] Mayr, J, Jedrzejewski, J, . Uhlmann, E, Donmez, M. A., W. Knapp, F. Härtig, K. Wendt, T. Moriwaki, R. Schmitt, P. Shore, C. Brecher, T. Würz, K. Wegener, (2012), Thermal Issues in Machine Tools, CIRP Annals - Manufacturing Technology, 61: 771-791

[12] Isert, S., (2011), Heat Transfer Through A Rotating Ball Bearing At, Low Angular Velocities, Sarah Isert, Utah State University, Mechanical and Aerospace Engineering, "Heat Transfer Through A Rotating Ball Bearing At Low Angular Velocities" (2011). All Graduate Plan B and other Reports. Paper 90.

[13] Fanuc (2018) Fanuc Robodrill a-DiBadv Series, datasheet , Fanuc corporation, 2016, Accessed: 2018-07-07 fanuc.co.jp/en/product/catalog/pdf/robodrill/RDRILLA-DiBADV(E)-02.pdf

[14] Marek J. (2017), Design of CMC machine tools, Praha: MM publishing, s.r.o., 2017. ISBN: 978-80-260-8637-6

[15] Zhaoping T, Jianping, S (2011) The Contact Analysis for Deep Groove Ball Bearing Based on ANSYS, 2011 International Conference on Power Electronics and Engineering Application, Procedia Engineering 23 (2011) 423 $-428$ 